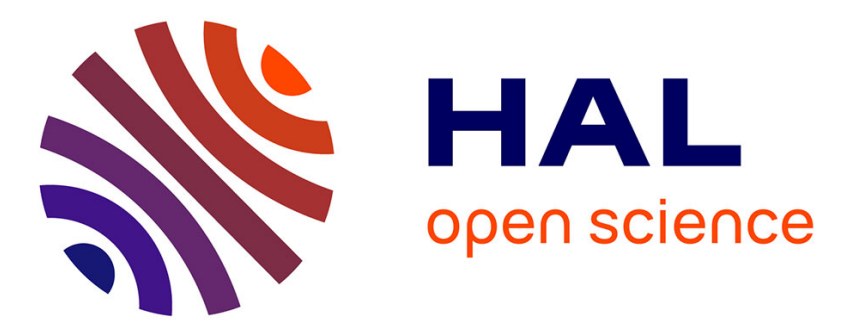

\title{
Application of the 2015/2016 EULAR recommendations for cardiovascular risk in daily practice: data from an observational study
}

Claire Immediato Daïen, Amandine Tubery, Guilhem Du Cailar, Thibault Mura, François Roubille, Jacques Morel, Jean Bousquet, Pierre Fesler, Bernard Combe

\section{To cite this version:}

Claire Immediato Daïen, Amandine Tubery, Guilhem Du Cailar, Thibault Mura, François Roubille, et al. Application of the 2015/2016 EULAR recommendations for cardiovascular risk in daily practice: data from an observational study. Annals of the Rheumatic Diseases, 2018, 77 (4), pp.625-626. 10.1136/annrheumdis-2017-211074 . hal-01761697

\section{HAL Id: hal-01761697 https://hal.science/hal-01761697}

Submitted on 22 Apr 2020

HAL is a multi-disciplinary open access archive for the deposit and dissemination of scientific research documents, whether they are published or not. The documents may come from teaching and research institutions in France or abroad, or from public or private research centers.
L'archive ouverte pluridisciplinaire $\mathbf{H A L}$, est destinée au dépôt et à la diffusion de documents scientifiques de niveau recherche, publiés ou non, émanant des établissements d'enseignement et de recherche français ou étrangers, des laboratoires publics ou privés. 


\section{Application of the 2015/2016 EULAR} recommendations for cardiovascular risk in daily practice: data from an observational study

The European League Against Rheumatism (EULAR) recently updated the recommendations for cardiovascular disease (CVD) risk management in patients with rheumatoid arthritis (RA). ${ }^{1}$ In contrast to the 2009 recommendations which advised to multiply by 1.5 the global CVD risk in the presence of certain RA-specific criteria, ${ }^{2}$ the $2015 / 2016$ update recommends to multiply by 1.5 the global CVD risk for all patients with RA. It also considers the use of carotid ultrasound to screen asymptomatic atherosclerotic plaques. Indeed, the majority of the CVD events occur in the 'low' and 'intermediate' risk groups and carotid plaque detection to classify patients improves cardiovascular risk prediction. ${ }^{3}$ The European Society of Cardiology guidelines classify patients with carotid plaque at very high CVD risk. ${ }^{4}$ Immediate statin use is indicated in those patients if low-density lipoprotein cholesterol is $\geq 0.7 \mathrm{~g} / \mathrm{L}^{4}$ In a post hoc analysis, we evaluated the impact of the updated 2015/2016 EULAR CVD recommendations as compared with the 2009 recommendations on CVD risk stratification and statin indication in a prospective cohort of 157 patients with RA who underwent a systematic CVD screening.

Out patients with RA were consecutively recruited by rheumatologists and referred to a daily clinicat Montpellier University Hospital between March 2014 and June 2015. The investigations included collection of medical history, physical examination, and calcu lation of the 10-year cardiovascular risk mortality using the total cholesterol/high-density lipoprotein cholesterol ratio Heart SCORE. ${ }^{2}$ A modified Heart SCORE (mSCORE) was used according to the 2009 EULAR (mSCORE 2009) ${ }^{2}$ and 2015/2016 guidelines (mSCORE 2015). ${ }^{1}$ Carotid ultrasonography was performed by experienced angiologists. Carotid plaque was assessed using standardised definition. ${ }^{5}$ The present study was approved by the medical ethics committee of Montpellier in accordance with the 2013 Declaration of Helsinki and with article R. 1121-3 of French public health law (number CPPQ2016.11.01).

The characteristics of patients who underwent the CVD screening are summarised in table 1.

The analysis was performed on the 144 patients with RA with both lipid assessment and carotid ultrasonography available. Compared with EULAR 2009 recommendations, application of the 2015/2016 update doubled the number of patients with high

Table 1 Characteristics of patients with rheumatoid arthritis who underwent cardiovascular screening

\begin{tabular}{ll}
\hline & $\mathrm{n}=157$ \\
\hline Age (years) & $61 \pm 10$ \\
Female (\%) & 72.6 \\
Body mass index $\left(\mathrm{kg} / \mathrm{m}^{2}\right)$ & $24.5(21.7-28.9)$ \\
Disease duration (years) & $13(6-19)$ \\
RF positivity (\%) & 69.9 \\
Erosion (\%) & 69.4 \\
DAS28-CRP & $2.4(1.7-3.3)$ \\
Ongoing steroids (\%) & 26.1 \\
Ongoing biological DMARDs (\%) & 73.1 \\
\hline
\end{tabular}

Data are no. (\%), median (IQR25-75) or mean \pm SD when applicable. All patients with RA fulfilled the American College of Rheumatology/EULAR 2010 criteria. DAS28-CRP, Disease Activity Score 28 joints; DMARDs, disease-modifying antirheumatic drugs; RF, rheumatoid factor.
Table 2 Comparison of the 2009 EULAR recommendations and the 2015/2016 update in 144 patients with rheumatoid arthritis

\begin{tabular}{|c|c|c|}
\hline mSCORE categories: $\mathrm{n}(\%)$ & 2009 & $2015 / 2016$ \\
\hline Moderate & $78(54.2)$ & $24(16.7)$ \\
\hline High & $32(22.2)$ & $6(4.2)$ \\
\hline Very high & $20(13.9)$ & $103(71.5)$ \\
\hline High + very high & $53(36.8)$ & $109(75.7)$ \\
\hline $\begin{array}{l}\text { Patients requiring immediate use of statins } \\
\text { depending on the recommendation used: } n(\%)\end{array}$ & $40(27.8)$ & $100(69.4)$ \\
\hline \multicolumn{3}{|c|}{$\begin{array}{l}\text { Presence of carotid plaques according to mSCORE } 2009 \text { categories: \% (n/total per } \\
\text { category) }\end{array}$} \\
\hline Low & \multicolumn{2}{|c|}{$21.4(3 / 14)$} \\
\hline Moderate & \multicolumn{2}{|c|}{$71.8(56 / 78)$} \\
\hline High & \multicolumn{2}{|c|}{$71.9(23 / 32)$} \\
\hline Very high & \multicolumn{2}{|c|}{$75.0(15 / 20)$} \\
\hline
\end{tabular}

or very high global CVD risk ( $75.7 \%$ vs $36.8 \%$ ) (table 2 ). This was explained by the presence of carotid plaques on ultrasound which reclassified $21.4 \%$ of the patients with low risk and $72 \%$ of those at moderate risk or high risk and very high risk. Statins would be indicated in $69.4 \%$ of the patients against $27.8 \%$ when applying the 2009 EULAR recommendations.

These data suggest that the EULAR CVD recommendation update will greatly impact the management of chronic inflammatory disease with frequent prescription of statins.

Our study included patients with severe RA as $73.1 \%$ were treated with biological disease-modifying antirheumatic drugs. This might explain the high frequency of carotid plaques detected. However, similar frequencies were previously reported. ${ }^{6}$

In patients with RA, statins are efficient to lower lipid levels, improve endothelial dysfunction ${ }^{78}$ and also seem to decrease CVD although data are limited. ${ }^{9-11}$ In a general population-based study, Schoenfeld et al found a $21 \%$ decrease in mortality in patients with RA treated by statins. ${ }^{10}$ In the randomised placebo-controlled TRACE-RA trial, including long-standing patients with RA without known atherosclerotic disease, the use of statins was associated with a $34 \%$ decrease in cardiovascular events. ${ }^{11}$ Based on those data, we could expect a $14 \%$ decrease in cardiovascular events overall in patients with RA if 2015 EULAR recommendation update is applied. However, this is only an extrapolation of data and more studies are needed to confirm the positive impact of statins on CVD events in patients with RA in primary prevention or with carotid plaque.

\section{Claire Immediato Daïen, ${ }^{1,2}$ Amandine Tubery, ${ }^{1}$ Guilhem du Cailar, ${ }^{3}$ Thibault Mura, ${ }^{4}$ François Roubille, ${ }^{5}$ Jacques Morel, ${ }^{1,2}$ Jean Bousquet, ${ }^{6}$ Pierre Fesler, ${ }^{3}$ Bernard Combe ${ }^{1,2}$ \\ 'Department of Rheumatology, Lapeyronie Hospital and Montpellier University, Montpellier, France \\ ${ }^{2}$ Institute of Molecular Genetics, Montpellier, France \\ ${ }^{3}$ Internal Medicine and Hypertension, Lapeyronie Hospital and Montpellier University, Montpellier, France \\ ${ }^{4}$ Department of Medical Information, Montpellier University, Montpellier, France ${ }^{5}$ Department of Cardiology, Arnaud de Villeneuve Hospital and Montpellier University, Montpellier, France \\ ${ }^{6}$ University Hospital, Montpellier, France}

Correspondence to Claire Immediato Daïen, Department of Rheumatology, Hôpital Lapeyronie, 371 Avenue du Doyen Gaston Giraud, 34295 Montpellier Cedex 5, France; cidaien@gmail.com

Acknowledgements We thank Marie-Christine Picot, Jean-David Cohen, Ariane Sultan, Rodolphe Bourret, Jean Ribstein, Antoine Avignon and Jean-Paul Cristol for development of the comorbidity clinic.

Contributors Conceptualisation: CID, JM, PF, JB, BC. Methodology: CID, PF, FR, TM. Software: TM, CID, PF. Formal analysis: CID, AT, TM. Investigation: CID, AT, GdC, JM, 
$B C, P F, F R$. Resources: CID, JM, PF, JB, BC. Writing (original draft preparation): CID, AT. Writing (review and editing): JB, FR, GdC, JM, BC, TM, PF. Supervision: CID, BC, PF, JB. Project administration: CID, BC, PF, JB.

Funding MACVIA-LR.

Competing interests $C I D$ has received honoraria from BMS, MSD, Pfizer, RocheChugai, and UCB, and research grants from MSD, Pfizer, Roche-Chugai and UCB. PLEASE REPORT SIMILAR COMPETING INTEREST AT THE END OF THE MANUSCRIPT

\section{REFERENCES}

1 Agca R, Heslinga SC, Rollefstad S, et al. EULAR recommendations for cardiovascular disease risk management in patients with rheumatoid arthritis and other forms of inflammatory joint disorders: 2015/2016 update. Ann Rheum Dis 2017:76:17-28.

2 Peters MJ, Symmons DP, McCarey D, et al. EULAR evidence-based recommendations for cardiovascular risk management in patients with rheumatoid arthritis and other forms of inflammatory arthritis. Ann Rheum Dis 2010;69:325-31.
3 Nambi V, Chambless L, Folsom AR, et al. Carotid intima-media thickness and presence or absence of plaque improves prediction of coronary heart disease risk: the ARIC (Atherosclerosis Risk In Communities) study. J Am Coll Cardiol 2010;55:1600-7.

4 Piepoli MF, Hoes AW, Agewall S, et al. Task Force Members. 2016 European Guidelines on cardiovascular disease prevention in clinical practice: The Sixth Joint Task Force of the European Society of Cardiology and Other Societies on Cardiovascular Disease Prevention in Clinical Practice (constituted by representatives of 10 societies and by invited experts) Developed with the special contribution of the European Association for Cardiovascular Prevention \& Rehabilitation (EACPR). Atherosclerosis 2016;252:207-74.

5 Touboul PJ, Hennerici MG, Meairs $S$, et al. Mannheim carotid intima-media thickness consensus (2004-2006). An update on behalf of the Advisory Board of the $3 \mathrm{rd}$ and 4th Watching the Risk Symposium, 13th and 15th European Stroke Conferences, Mannheim, Germany, 2004, and Brussels, Belgium, 2006. Cerebrovasc Dis 2007;23:75-80.

6 Corrales A, González-Juanatey C, Peiró ME, et al. Carotid ultrasound is useful for the cardiovascular risk stratification of patients with rheumatoid arthritis: results of a population-based study. Ann Rheum Dis 2014;73:722-7.

7 Ikdahl E, Hisdal J, Rollefstad S, et al. Rosuvastatin improves endothelial function in patients with inflammatory joint diseases, longitudinal associations with atherosclerosis and arteriosclerosis: results from the RORA-AS statin intervention study. Arthritis Res Ther 2015;17:279.

8 Rollefstad S, Kvien TK, Holme I, et al. Treatment to lipid targets in patients with inflammatory joint diseases in a preventive cardio-rheuma clinic. Ann Rheum Dis 2013;72:1968-74.

9 Sheng $X$, Murphy MJ, Macdonald TM, et al. Effectiveness of statins on total cholesterol and cardiovascular disease and all-cause mortality in osteoarthritis and rheumatoid arthritis. J Rheumatol 2012;39:32-40.

10 Schoenfeld SR, Lu L, Rai SK, et al. Statin use and mortality in rheumatoid arthritis: a general population-based cohort study. Ann Rheum Dis 2016;75:1315-20.

11 Kitas GD, Nightingale P, Armitage J. Trial of atorvastatin for the primary prevention of cardiovascular events in patients with rheumatoid arthritis (TRACE-RA). Ann Rheum Dis 2015;688. 